\title{
APLIKASI ALAT MUSIK TRADISIONAL GAMELAN JAWA BERBASIS ANDROID
}

\author{
Khotim Hidayati ${ }^{1)}$, Nur Nafi'iyah ${ }^{2)}$ \\ ${ }^{1)}$ Program Studi Teknik Informatika Universitas Islam Lamongan \\ ${ }^{2)}$ Dosen Fakultas Teknik Prodi Teknik Informatika Universitas Islam Lamongan \\ Email:hidaselena@gmail.com ${ }^{1}, \underline{\text { mynaff26@gmail.com }}{ }^{2}$
}

\begin{abstract}
Abstrak
Musik gamelan Jawa adalah karya seni musik tradisional yang merupakan produk seni dan budaya asli Indonesia yang perlu dijaga kelestariannya. Musik gamelan Jawa merupakan identitas bangsa Indonesia, yang sekaligus merupakan hasil karya seni musik tradisi yang sangat tinggi nilainya.Tujuan dari penelitian ini adalah untuk membangun aplikasi gamelan jawa sebagai media pelestarian budaya dan media pembelajaran instrumen gamelan dengan memanfaatkan perkembangan teknologi informasi. Sistem ini dibangun dengan menggunakan software eclipse yang sudah terpasang ADT, kemudian sistem diuji dengan SDK. Desain gambar gamelan menggunakan software Adobe Potoshop. Hasil penelitian memberikan kemudahan terhadap masyarakat untuk belajar mengetahui tentang gamelan jawa serta membantu memperkenalkan kebudayaan tradisional Indonesia dari perangkat mobile berbasis android.
\end{abstract}

Kata Kunci : Aplikasi Pengenalan Gamelan Jawa, Android, Eclipse

\begin{abstract}
Javanese gamelan music is the work of art of traditional music is a product of original Indonesian art and culture needs to be preserved . Javanese gamelan music is the identity of the Indonesian nation, which is also a work of art music tradition of very high value. The purpose of this research is to build applications Javanese gamelan as a medium of cultural preservation and learning media gamelan instruments by utilizing information technology development. The system is built using Eclipse software already installed ADT , then the system is tested with the SDK. Design images using Adobe software potoshop gamelan . The results of the study provide convenience to the people to learn to know about the Javanese gamelan and help introduce traditional Indonesian culture of mobile devices based on Android.
\end{abstract}

Keyword : Applications Introduction Javanese Gamelan, Android, Eclipse 


\section{PENDAHULUAN}

Dalam bab ini, diuraikan tentang latar belakang masalah, rumusan masalah, batasan masalah, tujuan penelitian, manfaat penelitian, metode penelitian dan sistematika penulisan dalam laporan penelitian yang berjudul APLIKASI PENGENALAN ALAT MUSIK TRADISIONAL "GAMELAN JAWA" BERBASIS ANDROID.

Beraneka ragam kebudayaan Indonesia tersebar dipulau-pulau yang terbujur dari Sabang sampai Merauke. Kebudayaan sebagai hasil dari peradaban manusia, berbagai bentuk hasil kebudayaan seperti adat istiadat, tarian, musik ataupun acara ritual, yang secara turun temurun dilestarikan oleh penduduk. Di Pulau Jawa terdapat beraneka suku bangsa yang memiki kebudayaan sendiri-sendiri. Jawa Tengah salah satu propinsi yang ada dipulau Jawa memiliki ciri khas kebudayaan yang tidak dimiliki oleh daerah lain. Arsitektur bangunan, pakaian adat, adat istiadat, acara ritual sampai kesenian, sehingga memberikan perbedaan Faktor historis yang mempengaruhi perbedaan ini.

Gamelan adalah satu alat musik tradisional khas jawa yang diturunkan dari generasi ke generasi yang sangat terkenal di pulau jawa dan banyak sekali diminati oleh masyarakat, baik dari memainkan hingga mendengarkan musik tersebut. Di era modern sekarang ini, budaya tradisionalpun mulai tergeser secara perlahan oleh budaya asing. Hal ini dikarenakan generasi muda tidak mau mengenal dan melestarikan budayanya sendiri, tetapi mereka lebih memilih mengenal lebih dalam budaya asing tersebut. ${ }^{1}$

Tujuan penelitian ini adalah :

1. Merancang aplikasi android media pengenalan alat musik tradisional "gamelan jawa" yang mudah digunakan dan difahami dan mengetahui nama-nama instrumen dalam "gamelan jawa".
2. Memperoleh hasil yang dapat dimengerti oleh user dengan mudah,sehingga apa yang dirancang dapat memberikan hasil yang optimal dan memberikan pengetahuan yang dibutuhkan kepada masyarakat mengenai alat musik tradisional "gamelan jawa".

Penelitian ini diharapkan mampu memberikan manfaat, sebagai berikut:

1. Sarana untuk pengembangan ilmu pengetahuan dibidang programer yang berbasis android.

2. Mengetahui alat-alat musik yang digunakan pada musik tradisional "gamelan jawa".

3. Pembelajaran berbasis android ini diharapkan dapat memberi manfaat secara praktis baik kepada guru maupun peserta didik dan masyarakat.

4. Meningkatkan sumberdaya manusia yang siap bersaing di dunia kerja yang berkwalitas.

5. Untuk menerapkan dan mengembangkan ilmu serta teori-teori yang telah didapatkan selama kuliah, sehingga ilmu yang dikuasai tidak bersifat teoritis belaka.

\section{PEMBAHASAN}

Aplikasi Android Media Pengenalan alat seni musik gamelan ini dibangun dengan menggunakan bahasa Java dengan IDE Eclipse. Menggunakan tool pendukung lain seperti Adobe Flash, Adobe Photosop CS6, Paint sebagai editor gambarnya. Rancangan sistem analisis memerlukan beberapa tahap pemodelan yaitu rancangan Use Case Diagram, rancangan Activity Diagram dan rancangan Squence Diagram.

Use Case Diagram merupakan rangkaian komponen yang saling terkait dan membentuk sistem secara teratur yang dilakukan oleh actor. Interaksi diantara komponen-komponen tersebut yang memperkenalkan suatu sistem yang akan dibangun. Seperti pada gambar berikut 


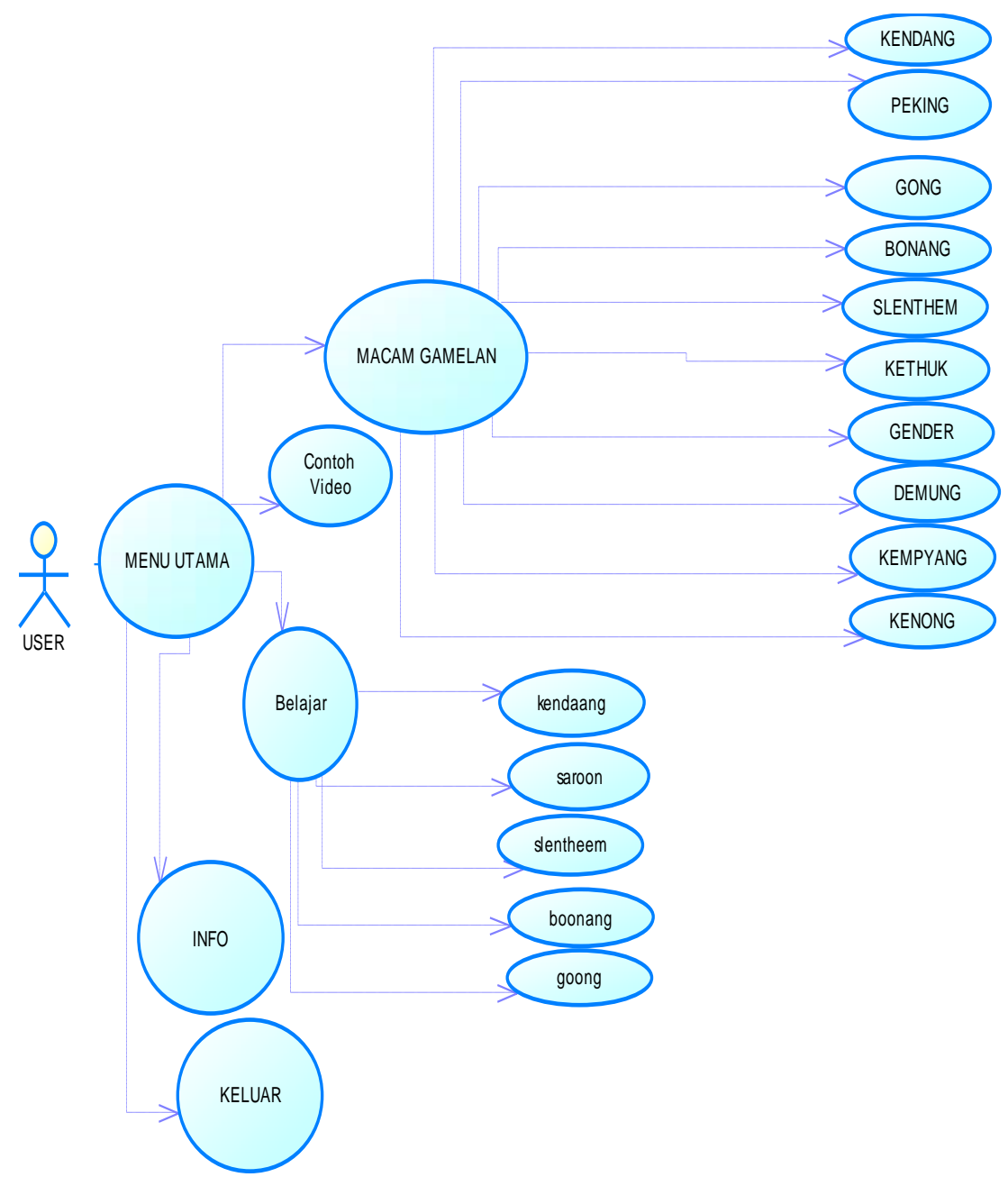

Gambar 1. Use Case Diagram

Activity diagram menggambarkan berbagai alir aktivitas dalam sistem yang sedang dirancang, bagaimana masing-masing alir berawal, decision yang mungkin terjadi dan bagaimana berakhirnya.

Activity diagram juga dapat menggambarkan proses paralel yang mungkin terjadi pada beberapa eksekusi, menggambarkan proses-proses dan jalur-jalur aktivitas dari level atas secara umum dan menggambarkan proses urutan aktivitas dalam sebuah proses. 


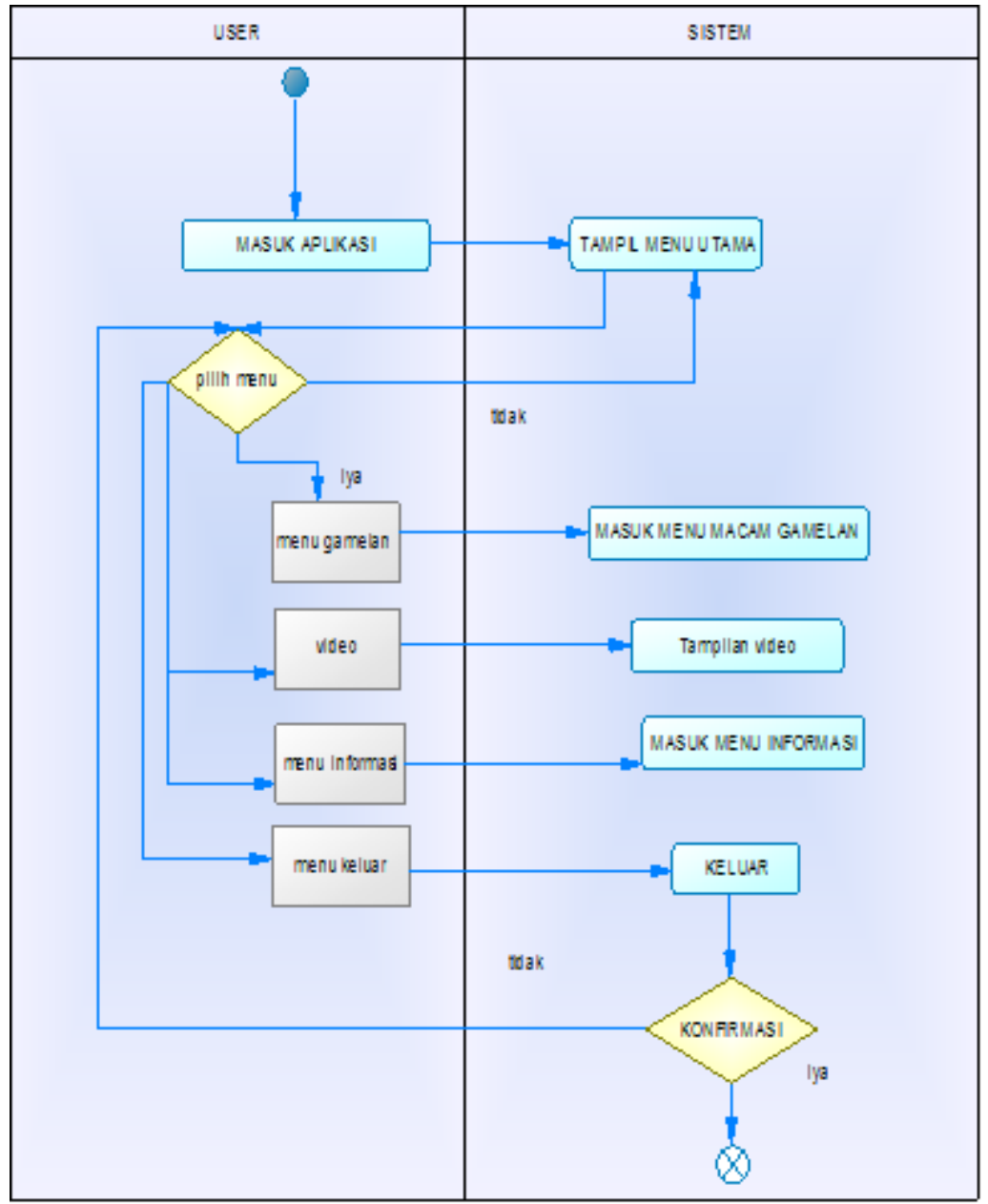

Gambar 2. Activity Diagram

Squence Diagram Aktivitas menu utama merupakan aktivitas yang dilakukan user untuk mandapatkan akses dan melakukan proses mengetahui informasi dari pengenalan. 


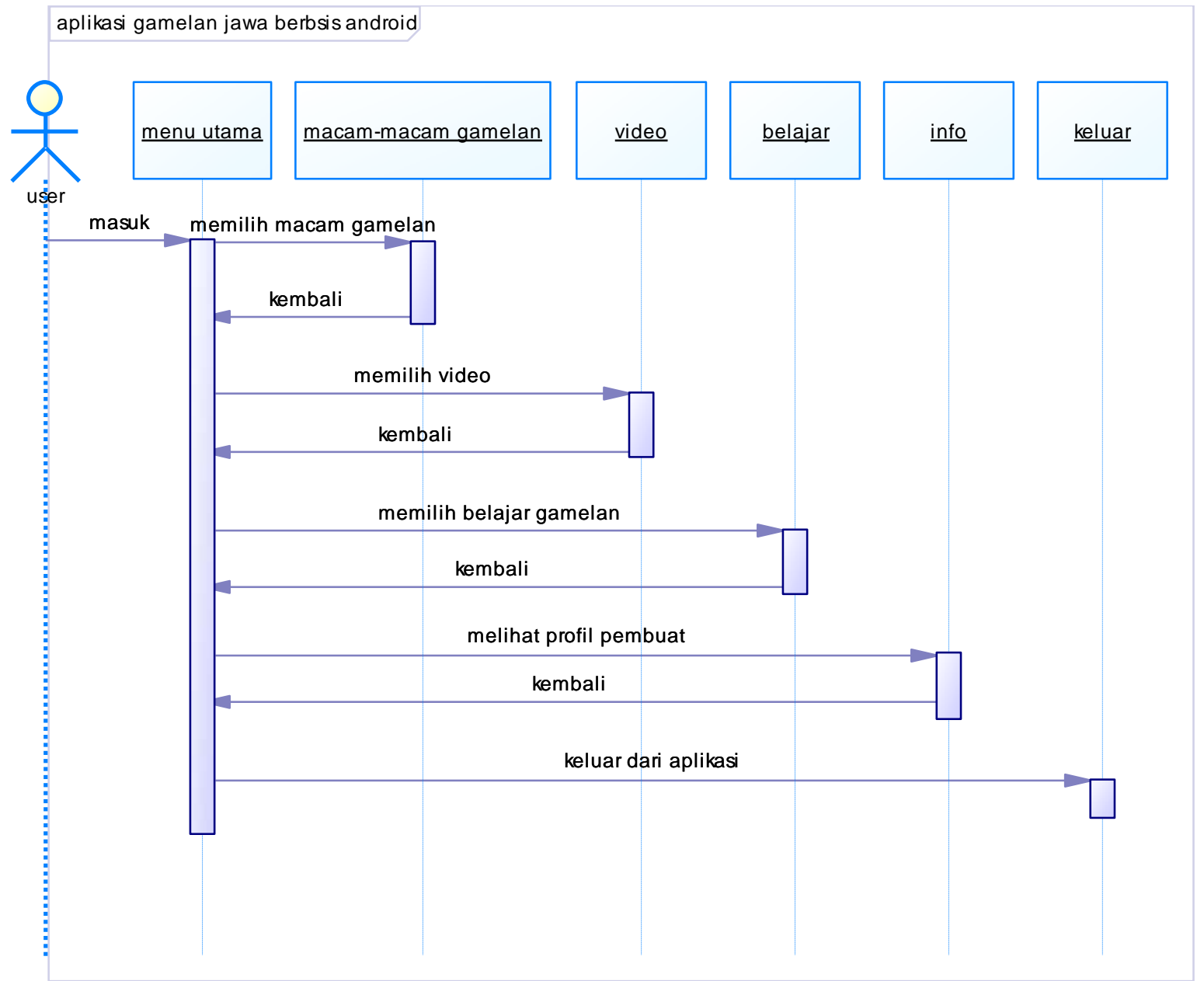

Gambar 3. Squence Diagram

\section{Hasil Uji Coba Sistem}

\section{Form Spalsh Screan}

Form loading adalah form yang mana menjadi sebuah form pembukaan saat user pertama kali menjalankan aplikasi ini dan sebelum masuk menu utama

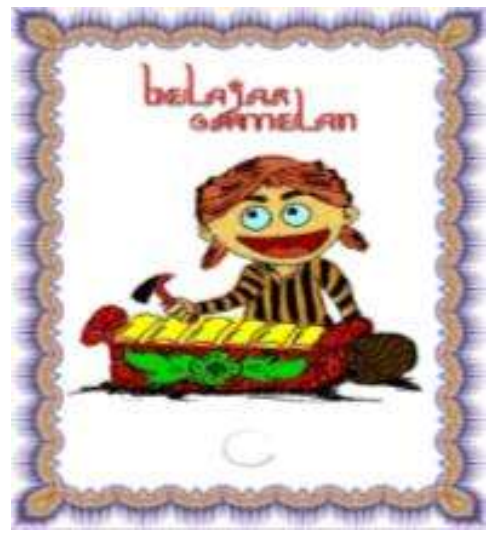

Gambar 4. Login

\section{Form Menu Utama}

Merupakan form pusat dari segala fitur yang ada pada aplikasi. Tampilan halaman menu utama berisi tombol menu macam 
gamelan, yang digunakan untuk menuju halaman macam gamelan jawa, tombol menu contoh video yang digunakan untuk menuju halaman video, tombol menu belajar untuk menuju halaman belajar gamelan, tombol menu info untuk menuju halaman info serta tombol keluar yang digunakan untuk keluar dari aplikasi.

Hidayati / Aplikasi Alat Musik Tradisional Gamelan Jawa Berbasis Android /JT,Vol 9 No.1, Maret 2017, pp 7 - 13

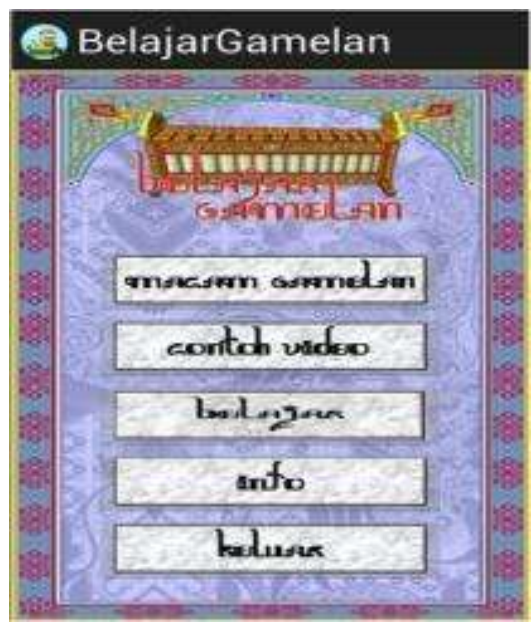

Gambar 5. Menu Utama

Form Macam Gamelan Jawa

Form macam gamelan jawa adalah form yang menjelaskan tentang pengertian dari beberapa instrumen gamelan jawa.

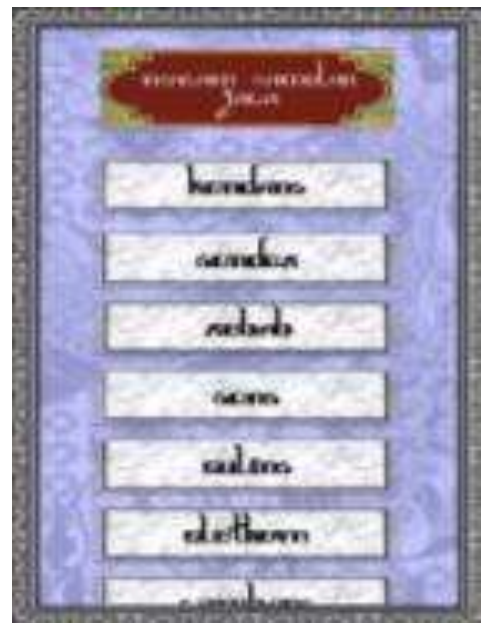

Gambar 6. Macam Gamelan

Form Contoh Video

Form contoh video adalah form yang menunjukkan video gamelan jawa.

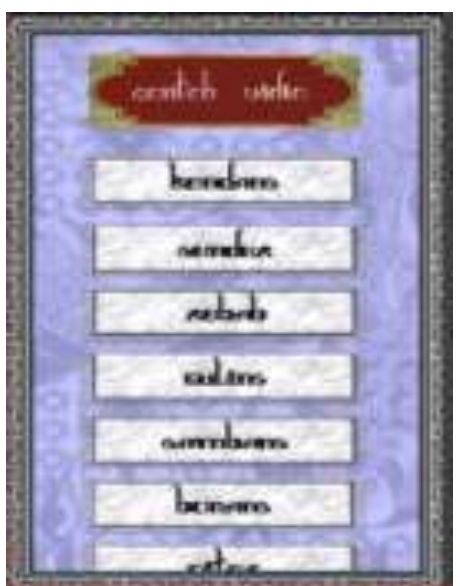

Gambar 7. Macam Video

Form belajar gamelan jawa adalah form yang menunjukkan tentang bunyi dari gamelan jawa. Tampilan form belajar gamelan jawa

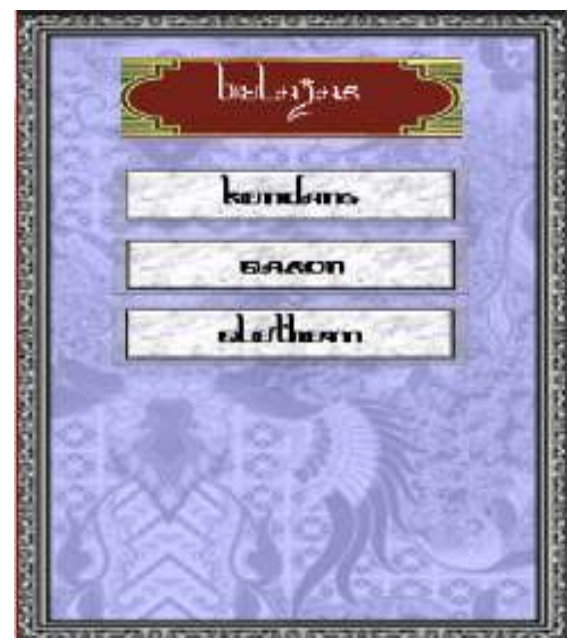

Gambar 8. Belajar

\section{KESIMPULAN}

Perancangan Aplikasi Alat Musik Tradisional Gamelan Jawa Berbasis Android dilakukan melalui beberapa tahap, yaitu tahap desain UML, tahab desain interface, tahap perancangan sistem, tahap analisis, tahap testing, tahap implementasi dan tahap penginstalan.

Implementasi aplikasi diuraikan dalam bentuk gambar atau printscreen dari aplikasi pengenalan, Berdasarkan aplikasi yang telah 
dibuat, aplikasi ini menggunakan bahasa Indonesia, desain tampilan aplikasi yang menarik, terdapat macam-macam gamelan, bunyi dan beberapa contoh video dari gamelan jawa yang telah dipaparkan. Informasi mengenai pengertian macam-macam gamelan jawa, dilengkapi gambar untuk memperjelas setiap informasi. Terdapat pilihan menu tentang aplikasi yang berguna untuk menjelaskan bagian-bagian dan manfaat masing-masing fitur. yang disertai dengan Hidayati / Aplikasi Alat Musik Tradisional Gamelan Jawa Berbasis Android /JT,Vol 9 No.1, Maret 2017, pp 7 - 13

2) Ningsih Murni Irian. 2012. Alat Musik Tradisional Nusantara. Bandung: Pringgandani.

3) Muljono,2014.Adaptif Gamelan sintetis Menggunakan Metode

Pitch shifting phase vocoder untuk Standarisasi Nada dan Media Pembelajaran Gamelan dalam Rangka Menuju Industri Kreatif Modern Nasional dinus.ac.id/wbsc/assets/dokumen/.../Lap... /laporanAkhir_Muljono_0604017101_.pd fDiakses pada 12 April 2016 pukul 13:12 keterangan dari gambar yang ditampilkan dan pembahasan tentang aktifitas pembuatan, perancangan dan pengembangan aplikasi.

\section{PUSTAKA}

1) Waridi,"tentang gamelan" https://onesgamelan.wordpress.com/2009/ 01/26/musik-gamelan-sebuah-catatan tentang-pendidikan-kehidupan-dankekaryaan/. Di akses pada 27 April 2016 pukul 12:15

4) Irianto Djoko Basuki, 2013. Pembelajaran Apresiasi Seni Musik Gamelan Jawa Dikelas X SMA Negeri 1 Malang https://www.google.com/search?q=Irianto +Djoko+Basuki+\%282013\%29\%2C+den gan+judul+Pembelajaran+Apresiasi+Seni + Musik+Gamelan+Jawa+Dikelas+X+SM A+Negeri $+1+$ Malang $\&$ ie $=$ utf $-8 \& o e=u t f-$ $8 \&$ client=firefox-b-ab Diakses pada 28 April 2016 pukul: 12:30 
